\title{
Arizona team spins its biggest telescope mirror so far
}

Tucson

THE giant mirror-making furnace at the University of Arizona took another spin on 25 April, and the first of two 3.5metre telescope mirrors came out glowing. This was the second trial for the Steward Observatory Mirror Laboratory's rotating furnace, which its designers say should make mirror-making less expensive and less time-consuming.

\section{IMAGE UNAVAILABLE FOR COPYRIGHT REASONS}

More than two tons of glass is loaded into the mould.

The honeycomb sandwich design results in a stiff, light mirror which can more easily be kept close to air temperature. This helps keep images crisp, according to J. Roger Angel, the University of Arizona astronomer who came up with the mirror design.

For this casting, it took 1.5 days to load the 5,000 pounds of borosilicate glass into the 6-metre furnace. Two hun- dred kilowatts were used to heat the glass to about $1,170^{\circ} \mathrm{C}$, and another 130 kilowatts were needed to keep it at that temperature. After about two hours at the peak temperature, the furnace was allowed to cool. After 27 hours, with the temperature below $600^{\circ} \mathrm{C}$, the spinning was stopped. Slow cooling will continue for six weeks to allow the glass to anneal. Next year the furnace will be expanded to 10 metres for making a 6.5metre mirror to upgrade the Multiple Mirror Telescope on Mount Hopkins in Arizona.

This first 3.5-metre mirror will be named after Marc A. Aaronson, the University of Arizona astronomer killed in an accident on Kitt Peak on 30 April 1987. It will be used in the Astrophysical Research Consortium telescope on Apache Point in New Mexico. That telescope will be the world's 14th largest and will be operated remotely by the five universities in the consortium, Princeton, the University of Chicago, New Mexico State, the University of Washington and Washington State.

Elizabeth Pennisi

France has signed an agreement to cooperate with Spain in the field of astrophysics, thus joining Denmark, Great Britain, Sweden and West Germany. The Themis Solar Telescope, developed by the French National Institute for Sciences of the Universe is to begin construction on the island of Tenerife in the Canaries next spring.

P.C.

\section{US astronomers have to choose which telescopes to keep}

Washington

Astronomers in the United States, their funding eroded by inflation over the past decade, now find themselves forced to choose between the maintenance of existing telescope facilities and the planning and construction of new ones. Although no hard decisions have yet been made, it seems inevitable that some of the smaller facilities at notable observatories such as Kitt Peak in Arizona and Cerro Tololo in Chile will be curtailed.

Kitt Peak and Cerro Tololo are run by the National Optical Astronomy Observatories (NOAO), which is operated by the Association of Universities for $\mathrm{Re}$ search in Astronomy (AURA) and supported financially by the National Science Foundation (NSF). NSF has given approval for several new projects, notably the Global Oscillations Network (GONG), a worldwide chain of solar telescopes, but has given NOAO no exthat modest budget items, such as paying journal page-charges for visiting astronomers, must now be sacrificed to keep the telescopes working.

In a letter to the US astronomical community earlier this year, Goetz Ortel, president of AURA, and Sidney Wolff, director of NOAO, described three strategies for survival: maintain existing operations at the expense of new projects; abandon all but the biggest present telescopes and concentrate on building for the future; or support only those facilities where NOAO can make a unique contribution to world astronomy. But even if the first plan were adopted, it is not clear that smaller telescopes such as the 1.5-metre at Kitt Peak would remain in operation.

Ortel says that the community has tra money to support them. This means

\section{All go for Canada and space station Edmonton, Alberta}

Canada's space ambitions took one step forward and one step back last month. On the plus side, the government has resolved the financial question raised by the extra Cdn\$388 million needed to pay for Canada's role in the design, development operation and use of the international space station being organized by the US National Aeronautics and Space Administration (NASA). But at the same time, the British decision not to participate in Radarsat, a remote sensing satellite (Nature 332, 669; 1988), has sent that project into limbo.

Canadian participation in the space station became a hot political question earlier this year when the estimated cost of participating climbed from $\mathbf{C d n} \$ \mathbf{8 0 0}$ million to nearly Cdn $\$ 1,200$ million. But Canada sees space station participation as crucial for sustaining future economic growth, and it seemed inevitable that the money would be found. Robert de Cotret minister of state for science and technology hailed the funding decision, calling space station participation "a measure of our technology maturity as a nation".

Enthusiasm in the scientific community was tempered by the fact that part of the additional funds needed will come out of a Cdn\$1,3000 million 5-year programme announced earlier this year to support science and technology. At a conference here entitled "University research and the future of Canada" there were rumblings of discontent as financially strapped research scientists wondered how much of the new money would would find its way to the Canadian granting councils, the primary source of funds for basic research. Without British support, Radarsat faces an uncertain future. Although the project is "far from dead" according to a government spokeswoman, she acknowledged that the prospects for finding a new partner are not bright.

Joseph Palca

reacted constructively to the crisis, and he has received thoughtful and imaginative responses from several astronomers. One suggestion is that universities could lease or take over operations which NOAO can no longer afford.

An underlying concern to the US community is that European astronomers are regaining an ascendancy they lost about fifteen years ago. Jacques Beckers, who was in charge of NOAO's National New Technology Telescope programme, has left to direct the corresponding European venture, the Very Large Telescope, which has been given financial support. If US astronomers are to compete in the future, says Ortel, painful choices must be made now.

David Lindley 